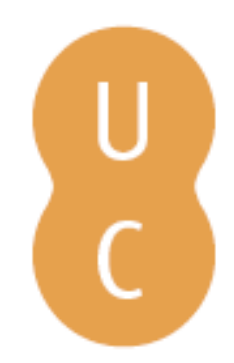

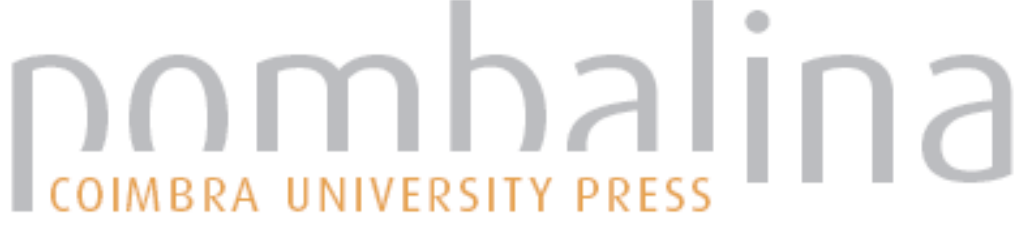

\section{República Popular da China}

\author{
Autor(es): $\quad$ Mendes, Carmen Amado \\ Publicado por: Imprensa da Universidade de Coimbra \\ URL \\ persistente: $\quad$ URI:http://hdl.handle.net/10316.2/38500 \\ DOI: $\quad$ DOI:http://dx.doi.org/10.14195/978-989-26-0995-9_14
}

Accessed : $\quad$ 26-Apr-2023 12:53:54

A navegação consulta e descarregamento dos títulos inseridos nas Bibliotecas Digitais UC Digitalis, UC Pombalina e UC Impactum, pressupõem a aceitação plena e sem reservas dos Termos e Condições de Uso destas Bibliotecas Digitais, disponíveis em https://digitalis.uc.pt/pt-pt/termos.

Conforme exposto nos referidos Termos e Condições de Uso, o descarregamento de títulos de acesso restrito requer uma licença válida de autorização devendo o utilizador aceder ao(s) documento(s) a partir de um endereço de IP da instituição detentora da supramencionada licença.

Ao utilizador é apenas permitido o descarregamento para uso pessoal, pelo que o emprego do(s) título(s) descarregado(s) para outro fim, designadamente comercial, carece de autorização do respetivo autor ou editor da obra.

Na medida em que todas as obras da UC Digitalis se encontram protegidas pelo Código do Direito de Autor e Direitos Conexos e demais legislação aplicável, toda a cópia, parcial ou total, deste documento, nos casos em que é legalmente admitida, deverá conter ou fazer-se acompanhar por este aviso.

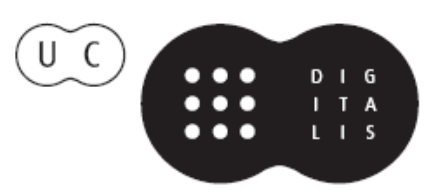




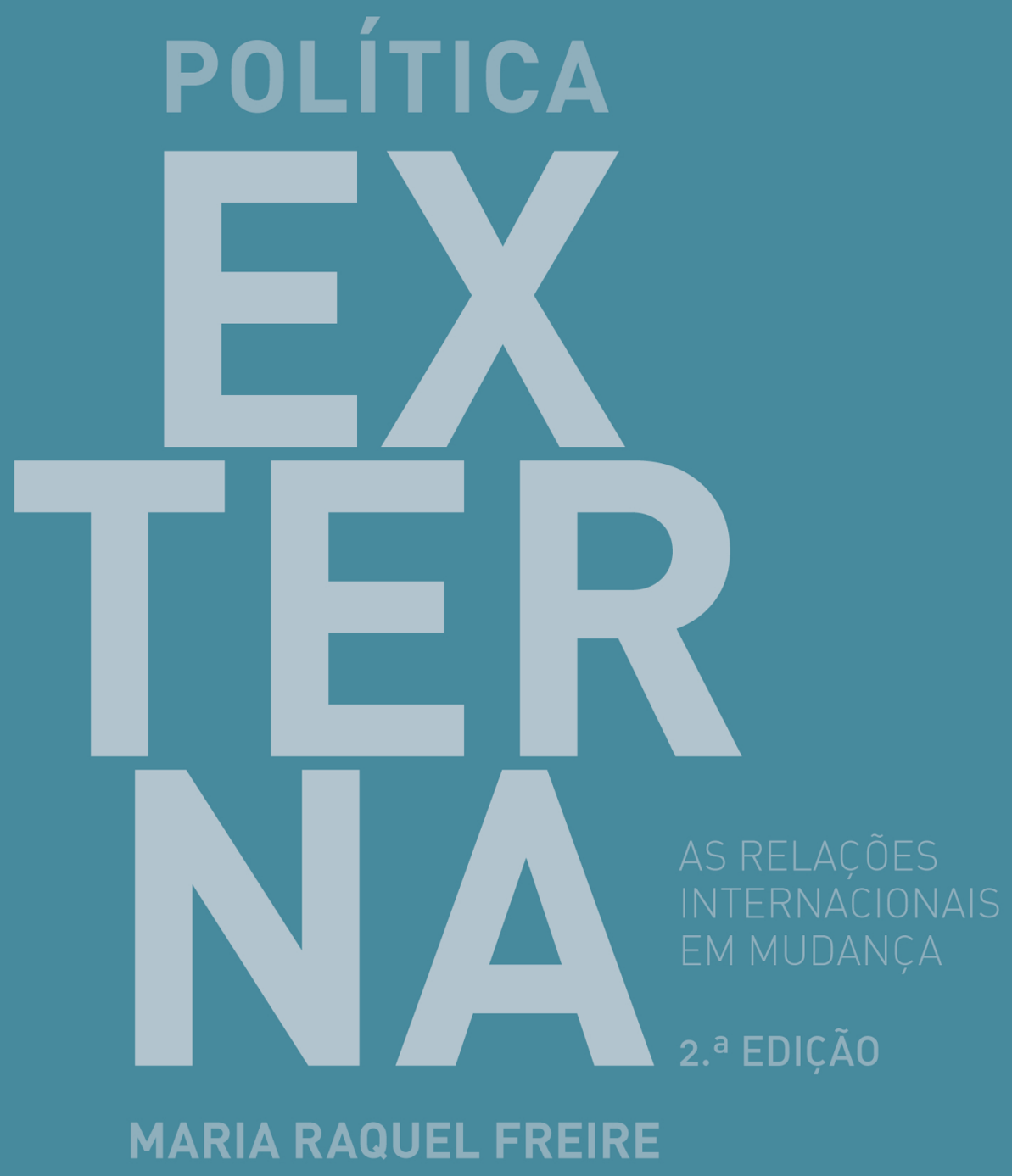

COORDENAÇÃO 


\section{CAPÍTULO 14 \\ REPÚBLICA POPULAR DA CHINA}

Carmen Amado Mendes

Este capítulo traça as principais linhas de política externa da República Popular da China (RPC). Após um breve enquadramento cultural, o texto segue um alinhamento histórico desde a fundação da RPC em 1949 à atualidade, refletindo sobre as alterações provocadas por fatores endógenos e exógenos no processo de tomada de decisão. A análise dos fatores endógenos descodifica a conceção tradicional de Relações Internacionais do Império do Meio, os antecedentes históricos com impacto na formulação da política externa contemporânea, o papel desempenhado nesta formulação pelas cinco gerações de líderes desde a fundação da RPC até à liderança atual, a caracterização do interesse nacional chinês e, por fim, a importância das tendências políticas do atual momento na tomada de decisão. Entre os fatores exógenos, com um impacto relevante na decisão, destacam-se as dinâmicas de competição e cooperação e as relações de reciprocidade estabelecidas entre a China e outros atores do sistema internacional. 


\section{Fatores endógenos na formulação}

\section{da política externa chinesa}

\section{A conceção tradicional de Relações Internacionais}

Entre os fatores endógenos que influenciam o processo de tomada de decisão em política externa, devemos destacar o contexto interno, ou seja, aspetos políticos, económicos, sociais, culturais e históricos que moldam as perceções dos líderes relativamente à situação e, consequentemente, enquadram a seleção da que é considerada a melhor abordagem. No caso chinês, a cultura e a história continuam a influenciar fortemente a postura adotada pelos líderes na cena internacional. As conceções tradicionais chinesas da ordem internacional são fundamentais para entender a política externa da China moderna.

Como é que os chineses entendiam as Relações Internacionais antes da chegada do Ocidente? Antes do século XIX não havia carateres em chinês para as palavras 'internacional', 'raça', 'país' facto que só se alterou com a entrada de potências estrangeiras na China. Os carateres da palavra 'China', 中国 ou 中國 - na escrita simplificada ou tradicional, ainda usada em Taiwan, Hong Kong e Macau (lê-se Zhongguo) - significam literalmente 'centro' e 'império/ nação', ou seja, Império do Meio. Havia um desinteresse profundo em relação aos outros 'países', ao 'internacional' e às outras 'raças'. A perceção de supremacia, para além de estar presente nesta assunção da centralidade, reflete-se na imposição de um sistema de vassalagem em que os países interessados no relacionamento com a China eram obrigados a pagar tributo ao Imperador chinês e os seus embaixadores e chefes militares tinham de lhe prestar homenagem através do kow-tow, uma prostração de corpo inteiro em que a testa tocava três vezes no chão, simbolizando a submissão absoluta. Esta cerimónia tornou-se o símbolo do choque entre as visões opostas que europeus e chineses tinham do mundo. Para um europeu, tal 
prostração significava que um embaixador (logo, o 'seu' rei) seria vassalo do Imperador chinês, gerando mal-entendidos bem conhecidos na história, nomeadamente na corte britânica. Em suma, o sistema tributário, através do qual as missões apenas podiam entrar no Império do Meio nos termos definidos por Pequim, mostra, claramente, o desinteresse chinês no relacionamento com o exterior.

Esta ideia da superioridade chinesa no plano internacional foi reforçada pelos ideais confucionistas de obediência, estratificação social e harmonia, cujas relações unidirecionais de poder e conceções hierárquicas são transpostas para o plano internacional. Segundo Confúcio, a sociedade chinesa está dividida em camadas: o Imperador está no topo, seguido dos académicos e funcionários da administração (cujo estatuto advém da aprovação nos exames, no ideal da meritocracia estabelecida por Confúcio), dos camponeses (a quem Confúcio atribui uma importância vital, por alimentarem a população), artesãos e, por fim, dos soldados (mal vistos por um filósofo que critica o recurso à violência) e comerciantes (percecionados como uma classe imprópria por deter o dinheiro do povo). De forma análoga, a sociedade internacional está hierarquizada: o Império do Meio, que se considera a "única cultura», está no topo, e engloba as nações vizinhas - Coreia, Vietname, Japão e restantes países asiáticos - que, estando perto, absorvem as ideias chinesas e conseguem ser mais civilizados, ao contrário dos europeus e africanos que são considerados bárbaros.

Que ilações nos permite tirar esta conceção tradicional das Relações Internacionais? Em primeiro lugar, ao contrário das normas ocidentais atuais, que refletem uma perceção da cena internacional como palco da competição entre Estados iguais, à imagem dos ideais de construção de sociedades igualitárias, a cultura chinesa não tem enraizadas conceções de igualdade mas sim de hierarquia, quer no plano interno - ao nível da família, da sociedade e do Estado - quer externo, no relacionamento com os restantes atores do sistema. Isto 
vai servir de base para argumentarmos que as atuais declarações chinesas sobre a necessidade de assegurar a igualdade e democracia nas Relações Internacionais não passam de retórica que cairia por terra se Pequim conseguisse atingir a tão desejada hegemonia e voltasse a ser o Império do Meio. Esta retórica deu os primeiros passos com Mao Zedong (Mao Tsé-Tung), que refutou os princípios hierárquicos confucionistas em troca do igualitarismo, não só em termos de construção da sociedade ideal mas também no plano internacional ${ }^{118}$; mas apesar de ser usado nos discursos não reflete, na sua essência, o pensamento dos atuais líderes.

Em segundo lugar, o sistema de vassalagem revela o desinteresse chinês na aproximação a outros povos e o sentimento de superioridade de então. Este sistema funcionou durante bastante tempo e permitiu a manutenção da paz; o que é notável, se compararmos com a situação na Europa da época. Estando longe dos seus vizinhos e vendo a sua superioridade respeitada, o Império não temia ameaças à civilização chinesa e não sofria invasões (o que explica, em parte, a sua incapacidade para responder à invasão europeia no século XIX) e não mostra interesse em recorrer à guerra. Isto é revelado nas descrições dos primeiros comentadores europeus que visitaram a China: Marco Polo, um visitante controverso (há quem diga que os seus escritos são baseados em leituras e não nos 17 anos que diz ter vivido na China, no séc. XIII) caracterizava o Império do Meio como uma «ditadura, tamanho colossal, rica em comércio, altamente urbanizada, inventiva em negócios comerciais, fraca nos modos de guerra" (Spence, 1998: 3). Mesmo nos séculos XVI-XVII manteve-se a perceção de que o Império do Meio era muito fraco em

118 Mao, embora tivesse uma visão de igualitarismo entre os Estados, percebeu claramente o modelo bipolar do sistema internacional e a posição desvantajosa da China. De forma estratégica, responde com a Teoria dos Três Mundos, criando um terceiro pólo: uma China unida ao Terceiro Mundo, disputando no terreno a hegemonia soviética na liderança do Movimento Comunista Internacional. 
termos militares, uma vez que tinha uma política de não-agressão em relação aos seus vizinhos. Estas análises servem hoje de base aos argumentos de que a China não é um poder bélico mas sim pacifista e que os seus slogans de "ascensão pacífica» e "paz e desenvolvimento" são genuínos.

Em terceiro lugar, o facto do Império do Meio permitir aproximações externas (embora segundo as suas regras) mas não mostrar particular interesse nelas, partilhando os conhecimentos da civilização chinesa com os povos vizinhos e com os «bárbaros" sem no entanto impor esta partilha, revela a ausência de crença missionária e obsessão em espalhar a civilização ${ }^{119}$. Isto contrasta fortemente com a cultura ocidental, apologista das missões, ou seja, na imposição da sua forma de pensar aos outros povos, em termos religiosos (Cristianismo), sociais (Direitos Humanos), políticos (Democracia) e económicos (Liberalismo). Mais à frente veremos que este contraste é hoje visível no choque entre o chamado "Consenso de Washington" e o "Consenso de Pequim": a postura arrogante de que o Ocidente sabe como é que as outras civilizações se devem governar é posta em causa por uma abordagem que não exige pré-condições comportamentais para o estabelecimento de relações de interesse mútuo.

\section{Antecedentes históricos}

Em relação aos aspetos históricos que mais influenciam o contexto de tomada de decisão na política externa chinesa, destaca-se a vitória da Grã-Bretanha na Guerra do Ópio de 1840 e a assinatura do Tratado de Nanquim, que lhe cedeu a colónia de Hong Kong, abrindo o precedente à ocupação da China por potências estrangeiras e à imposição de direitos de extraterritorialidade (aplicação da lei

119 De assinalar, no entanto, que durante a liderança de Mao Zedong a tentativa de impôr a visão chinesa do marxismo-leninismo aos países do Terceiro Mundo resultou numa luta ideológica com a União Soviética. 
dos países ocupantes a crimes cometidos pelos seus nacionais na China). Aos tratados que regem essa ocupação, naquele que o povo chinês considera ter sido o "Século de Humilhações", os líderes da China chamam "Tratados Desiguais», por eles considerados inválidos à luz do direito internacional, uma vez que foram impostos por potências ocupantes. Este período histórico, que à partida parece longínquo do contexto de tomada de decisão atual, não foi apagado da memória coletiva, avivada em momentos críticos de fragilidade chinesa perante os restantes atores do sistema internacional; ou seja, tudo o que envolva 'perder a face', como foi o caso da reação internacional à repressão chinesa das manifestações tibetanas em vésperas dos Jogos Olímpicos de 2008.

'Face' é prestígio, reputação atingida através da prosperidade, do sucesso e da ostentação. Este conceito aplica-se quer ao indivíduo em relação à sociedade civil - uma pessoa tem 'face' se a sociedade confia na sua integridade moral - quer a um país em relação à sociedade internacional. Pode ganhar-se 'face', escolhendo cuidadosamente o ambiente e o contexto em que se vai desenrolar a interação, tendo cuidado com as aparências ou adotando comportamentos específicos de forma a transmitir uma imagem positiva e um estatuto elevado durante os momentos de relacionamento com os outros. Mas também se pode perder 'face', quer por culpa própria, caso se adotem comportamentos desadequados, quer por intervenção de terceiros (ver Bond, 2008: 225 e 246). Em termos diplomáticos e negociais, 'face' passa por estabelecer a negociação sem fechar portas e arranjar sempre uma compensação mesmo quando se vence, 'carta' essa que pode ser exibida internamente como contrapartida: nenhum perde tudo; todos ganham. Os exemplos históricos acima referidos estão registados na memória chinesa como insultuosos e humilhantes, resultando numa perda de 'face' motivada pela arrogância estrangeira. Estes sentimentos de injustiça e vitimização ainda hoje condicionam fortemente a formulação da política externa chinesa, não 
só em relação ao Ocidente, mas também em relação ao Japão que, ao ser uma potência asiática, ainda traumatizou mais a China com a sua demonstração de superioridade evidenciada na brutalidade das invasões perpetradas em território chinês durante a II Guerra Mundial: a ausência de um sinal claro de arrependimento por parte dos líderes japoneses tem contribuído fortemente para exacerbar atitudes nacionalistas no vizinho asiático.

Para além do desejo de vingança das opressões estrangeiras, a herança histórica também deixou o seu rasto na obsessão coletiva pela restauração da integridade territorial, a que a política de reunificação nacional dá voz. A preocupação, para além de controlar regiões com tendências separatistas como é o caso do Tibete e do Xinjiang, passa pela recuperação dos territórios 'perdidos'. A forma entusiasta como o povo chinês celebrou o regresso de Hong Kong e Macau, em 1997 e 1999, e o aproveitamento feito pelas autoridades centrais que incentivaram o despertar do nacionalismo com base em sentimentos anticoloniais, refletem essas duas dinâmicas: por um lado, a libertação do imperialismo; por outro, o sonho de um país forte e unido. Estas dinâmicas exigem também a recuperação das pequenas ilhotas do Mar do Sul da China (Spratly) e no Pacífico (Diaoyutai), cujas águas são ricas em recursos energéticos, mas principalmente da ilha de Taiwan. Como é que Taiwan se tornou o corolário da política de reunificação nacional? Importa, mais uma vez, recordar a história.

A República da China, fundada em 1912 por Sun Yat-sen, dirigente do Partido Nacionalista (Kuomintang), que levou a que o último Imperador, Pu Yi, abdicasse, foi abanada pela já referida invasão japonesa em 1937. A partir da capitulação do Japão em 1945, a guerra civil entre comunistas e nacionalistas ganhou novo fôlego e terminou em 1949 com a vitória de Mao Zedong sobre Chiang Kai-shek, sucessor de Sun Yat-sen na liderança do Kuomintang. A 1 de outubro desse ano, Mao proclamou a República Popular 
da China; Chiang refugiou-se com o exército do Kuomintang em Taiwan, ilha que tinha sido recentemente libertada pelos invasores japoneses, criando o Governo da República da China no exílio. Durante o início da Guerra Fria, a República da China em Taiwan foi reconhecida pela Organização das Nações Unidas (ONU) como o único governo legítimo da China mas, com os votos das novas nações independentes africanas cujos movimentos de libertação tinham sido apoiados por Pequim e a evolução dos interesses do bloco ocidental, o assento da China foi transferido para Pequim. $\mathrm{O}$ apoio norte-americano a Taipé, no entanto, manteve-se inalterável, tendo um impacto evidente nas relações bilaterais entre Washington e Pequim.

Do ponto de vista chinês, Taiwan é uma província chinesa "renegada", onde se refugiaram os derrotados na guerra civil, cujos descendentes não têm qualquer direito em ocupar um território que pertence, de forma legítima, à China continental. O facto do conflito no Estreito de Taiwan ser percecionado como uma questão interna leva os líderes chineses a recusar qualquer interferência externa. Isto tem um impacto inegável na política externa chinesa, não só no que diz respeito às relações com os Estados Unidos da América e com o Japão, que possui um poderosíssimo lobby pró-Taiwan, mas também com o resto do mundo, particularmente com os países que mantêm relações diplomáticas com Taipé. A questão de Taiwan tem uma importância simbólica inestimável em termos de identidade nacional, pois tem sido usada pelas cinco gerações de líderes (ver quadro 1) para reforçar o sentimento nacionalista e de pertença coletiva. Assim, o seu impacto na contextualização no processo de tomada de decisão chinês não deve, jamais, ser menosprezado.

Para uma civilização em que a noção de tempo é bem diferente da ocidental, a memória histórica não é curta e a identidade do povo constrói-se com raízes num passado por vezes longínquo, 
como revelam as manifestações de orgulho nacionalista e a ênfase posta na política de reunificação nacional. Estes fatores endógenos explicam a influência do contexto interno na perceção dos fatores exógenos e nas reações que eles provocam. As históricas palavras de Mao na praça de Tiananmen aquando da fundação da RPC, "a China levantou-se!», ecoam desde então nas cabeças de todos os chineses: o Século das Humilhações seria vingado a seu tempo.

\section{o papel dos líderes}

Ainda hoje recordado como o "Libertador" da China (a sua imagem num cartaz gigante pesa sobre a simbólica praça de Tiananmen, no coração de Pequim, e o mausoléu com o seu corpo é aí diariamente visitado), Mao Zedong conseguiu, de facto, unificar o país. No entanto, abriu um novo período de instabilidade, ao extravasar o ódio profundo que cultivou contra os «imperialistas", que tinham repartido o Império do Meio, a todos os "elementos contrarrevolucionários", aplicando a "purificação moral" ao país inteiro, incluindo a vários dirigentes políticos que foram perseguidos. A partir de 1966, os Guardas Vermelhos da Revolução Cultural criam um clima de terror e de caos em Pequim que só termina com a morte de Mao em 1976. Após dois anos de convulsões e disputas de liderança, em 1978 Deng Xiaoping, que passara seis anos em 'reeducação' condenado a trabalho manual, foi restabelecido como Chefe do Estado-Maior do Exército Popular de Libertação e abre uma nova página na história da China. Apelando à modernização do país e às reformas, o "pequeno timoneiro" autoriza os camponeses a vender uma parte da sua produção no mercado livre, inicia a descoletivização da agricultura, cria as famosas Zonas Económicas Especiais, substitui as subvenções do Estado por empréstimos bancários e autoriza as cidades costeiras a atrair investimento estrangeiro. Mas, apesar de criar um sistema económico socialista de mercado, divulgando o slogan «enriquecer é glorioso!», Deng não aceita que a modernização política preceda a 
económica, ao contrário da perestroika soviética. Em junho de 1989, não se opõe a que o Primeiro Ministro Li Peng afaste os líderes mais reformistas e manda avançar os tanques do Exército contra os manifestantes que protestavam na praça de Tiananmen contra os efeitos desestabilizadores das reformas económicas e contra a corrupção.

De que forma é que estes dois líderes decisivos na história da RPC marcaram a sua política externa? Mao manteve uma atitude hostil em relação ao exterior, combinando-a com o recurso ao modelo soviético; desinteressado pela política externa, delegou esta pasta no Primeiro Ministro Zhou Enlai. Deng, num contexto de equilíbrio da máquina burocrática entre tendências conservadoras e radicais, afastou os elementos das Forças Armadas das posições centrais de decisão política. Em relação ao mundo exterior, o dinamizador das reformas económicas mudou gradualmente a tradicional abordagem da China, fechada sobre si mesma, para uma abertura progressiva ao exterior. Esta postura foi intensificada pelos líderes da terceira geração (ver quadro 1) em que Jiang Zemin, líder menos carismático, manteve a política do seu antecessor, abrindo o Partido aos empresários e aos que enriqueceram com a privatização da economia e tornando Xangai o competidor direto de Hong Kong. Nesta linha de continuidade, a política externa conduzida pelo seu sucessor, Hu Jintao, foi formulada em função da política económica da RPC, onde a atração de Investimento Direto Estrangeiro, o acesso a recursos naturais e a procura de mercados para escoar a produção, foram as prioridades, num modelo económico assente nas exportações e, consequentemente, dependente do exterior. Com a subida ao poder de Xi Jinping e da chamada quinta geração de líderes, o crescimento económico continua a ser uma questão prioritária, mas o discurso político, nos planos interno e externo, é cada vez mais assertivo. 


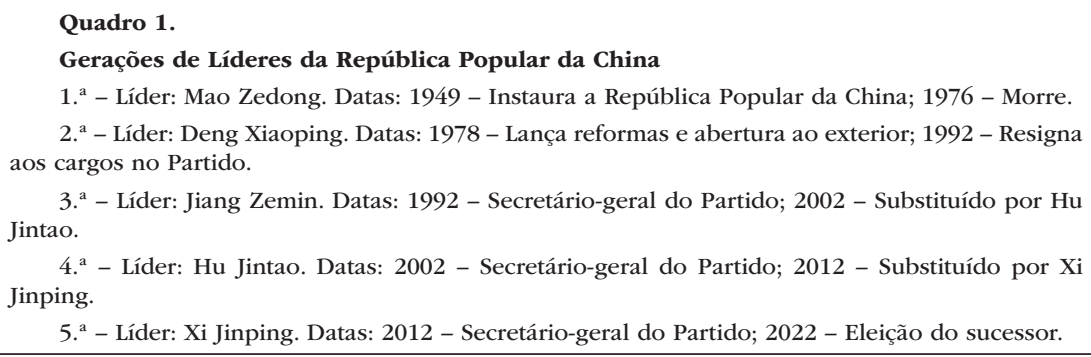

3. a - Líder: Jiang Zemin. Datas: 1992 - Secretário-geral do Partido; 2002 - Substituído por Hu

4. ${ }^{a}$ - Líder: Hu Jintao. Datas: 2002 - Secretário-geral do Partido; 2012 - Substituído por Xi

5. ${ }^{\text {a }}$ - Líder: Xi Jinping. Datas: 2012 - Secretário-geral do Partido; 2022 - Eleição do sucessor. Jintao. Jinping.

Neste contexto, importa analisar a importância, na formulação da política externa chinesa, da elite política, ou seja, dos vários elementos que compõem determinada geração de líderes, para além do Presidente. Numa notória confusão de poderes entre Estado, Partido Comunista Chinês (PCC) e Exército, as mesmas personalidades ocupam o topo das três instituições, dominando o processo de tomada de decisão, tendencialmente vertical, salvaguardando o papel dirigente do partido e evitando o colapso do socialismo. Os indivíduos mais velhos, embora possam não estar já formalmente em funções, exercem o seu poder num círculo de decisão paralelo à burocracia estatal, geralmente através de cédulas do PCC, e são consultados pelos líderes em funções, apoiando a ascensão na hierarquia do Partido e do Estado de um sucessor. Apesar de terem sido feitas algumas tentativas para 'horizontalizar' o processo de tomada de decisão, nomeadamente por Deng, ao afastar militares de carreira de cargos políticos, a geração de Hu seguiu a tradicional lógica de bastidores do politburo, de concentração das decisões importantes no topo da hierarquia e num pequeno círculo de líderes que tem pouco a ver com a estrutura formal do poder. Assim, podemos questionar-nos sobre o peso da personalidade do líder por oposição à burocracia ou mesmo à ideologia na orquestração da política externa chinesa. Desde Mao e Deng que a RPC não tinha um líder tão carismático como $\mathrm{Xi}$, sendo que os primeiros tinham mais constrangimentos burocráticos e ideológicos. Ainda hoje, não obstante a evolução visível nas ações externas chinesas, é inegável a preocupação com a formu- 
lação do discurso e dos slogans, de forma a colar argumentos marxistas a um socialismo "com características chinesas" (ver discursos e princípios do quadro 2 e citações oficiais incluídas neste capítulo).

De referir ainda a existência de três importantes grupos de pressão: militares, intelectuais e empresários procuram influenciar os líderes chineses na tomada de decisão, a par dos inúmeros think-tanks na área da política externa e de um grupo fechado ligado à Escola do Partido que funciona na dependência direta do Presidente. Os militares foram obrigados a assumir um papel mais passivo na sequência de Tiananmen e das já referidas medidas adotadas por Deng mas, sendo a modernização militar e o reforço da capacidade defensiva e ofensiva chinesa uma prioridade nacional, esta tendência está a alterar-se. Quanto aos intelectuais, assumem tendencialmente um papel consultivo da elite política, visível no enquadramento que lhes é dado pela Academia Chinesa de Ciências Sociais, um think tank encarregue de elaborar relatórios que apoiam a tomada de decisão do Governo chinês. No entanto, à medida que o sistema se foi abrindo, alguns saíram da sombra da elite política, ganhando autonomia, enquanto outros, afastados em Tiananmen, regressaram à China. Por fim, paralelamente à emergência económica da China, o grupo de pressão dos empresários, defendendo interesses comerciais individuais e privados, tem ganho força.

\section{O interesse nacional}

Outro dos fatores endógenos presente aquando da tomada de decisão em política externa é o interesse nacional, que reflete os grandes desígnios a salvaguardar para garantir a sobrevivência da nação, justificando, por isso, o empenho de todos os recursos; esse interesse reflete-se na formulação de objetivos vitais/permanentes e conjunturais, de acordo com as capacidades reais do Estado. Ao funcionar como o garante da unidade entre os membros de uma comunidade, o interesse nacional é, muitas vezes, distorcido por re- 
gimes ditatoriais. As autoridades chinesas, para defender um regime de partido único e evitar a fragmentação territorial, propagandeiam a ausência de alternativa ao Partido Comunista Chinês, cuja manutenção no poder continua a ser, desde 1949, um objetivo vital. A forma como este objetivo é atingido tem variado de geração para geração de líderes. Se Mao Zedong confiava no marxismo-leninismo enquanto ideologia aglutinadora, a geração de Hu Jintao recorreu muito mais ao nacionalismo como fonte de legitimidade do regime. Ao explorar os sentimentos patrióticos de pertença à nação de origem, o nacionalismo tem raízes históricas. No caso chinês, estas raízes remontam ao Século das Humilhações e decorrentes sentimentos de vitimização, conforme já foi referido, e assumem uma vertente ideológica para garantir a estabilidade política que tem, então, sido um objetivo permanente da RPC, refletindo-se, na atualidade, numa política externa assertiva relativamente ao Japão e numa inflexibilidade relativamente à política de reunificação nacional, como já foi referido.

O interesse nacional chinês passa também por garantir a manutenção dos níveis de crescimento económico que, por sua vez, têm ajudado a alimentar o nacionalismo e, consequentemente, a legitimar a presença do PCC no poder. Dois objetivos conjunturais desempenham aqui um papel importante: assegurar a procura de recursos naturais, objetivo esse que resulta numa política externa arrojada com presença em vários pontos do globo; e a busca de estabilidade regional, essencial à manutenção desse crescimento, refletindo-se numa postura muito pragmática da China em relação aos seus vizinhos. Embora dando continuidade a estes objetivos, $\mathrm{Xi}$ Jinping tem adotado uma postura muito mais assertiva e, desde o seu primeiro discurso como Presidente, tem proclamado o «sonho chinês» de prosperidade e de rejuvenescimento nacional:

The Chinese people are striving to fulfill the Chinese dream of the great renewal of the Chinese nation. The Chinese dream is 
about prosperity of the country, rejuvenation of the nation, and happiness of the people. It reflects both the ideal of the Chinese people today and our timehonored tradition to seek constant progress. The Chinese dream will be realized through balanced development and mutual reinforcement of material and cultural progress. (Xi, 2014)

Este slogan poderoso tem uma dimensão interna e externa. Internamente, a prosperidade dos cidadãos está ligada à 'responsabilidade' dos quadros do PCC, assinalando que os níveis de corrupção, que se vinham intensificando desde a era de Jiang Zemin, não são compatíveis com a melhoria de vida dos cidadãos. No plano externo, o sonho usa o nacionalismo para a prossecução dos objetivos vitais e conjunturais, procurando dar voz à China na cena regional e internacional.

\section{O momento}

Qualquer análise dos fatores endógenos na formulação da política externa de um país deve ter em conta o momento específico em que ela é formulada. No momento atual, são várias as tendências que influenciam o processo chinês de tomada de decisão. Em primeiro lugar, a crise civilizacional, com início no Século de Humilhações, agravou-se a partir de 1989 com o massacre de Tiananmen e a perda de credibilidade do comunismo. A substituição do Confucionismo pelos princípios do marxismo-leninismo enquanto fator ideológico aglutinador da sociedade revelar-se-ia dramática com a dissolução da ex-URSS (União das Repúblicas Socialistas Soviéticas). Este vazio espiritual do povo chinês tem vindo a ser preenchido pela atual geração de líderes com o recurso ao nacionalismo ${ }^{120}$. Por este

120 Em chinês 'nacionalismo' e 'patriotismo' são a mesma palavra, literalmente o 'amor pela terra-mãe', tendo consequentemente uma conotação positiva. 
motivo, a questão de Taiwan assume uma importância inestimável do ponto de vista identitário, influenciando de forma constante as relações da RPC com todos os países que dalguma forma apoiam Taipé, incluindo o Japão e os EUA, e estando presente em qualquer negociação que a China faça, por exemplo com a União Europeia (qualquer ator que queira relacionar-se com Pequim deve reiterar a política da 'China única', reconhecendo a RPC como a sua legítima representante). Em terceiro lugar, o fim da URSS e da luta ideológica sino-soviética alterou o relacionamento com a Rússia, com quem a China passou a estabelecer dinâmicas de rivalidade mas também de cooperação. Em quarto lugar, a relação da China com a economia mundial alterou-se radicalmente, passando de uma postura desinteressada e fechada a um crescente interesse, envolvimento e dependência. Por fim, os líderes chineses recorrem cada vez mais a uma nova diplomacia multilateral, participando em organizações regionais e internacionais.

\section{Fatores exógenos na formulação da política externa chinesa}

\section{Dinâmicas de competição vs. cooperação}

Apresentados os fatores endógenos, vamos agora analisar os elementos externos que influenciam o processo de decisão chinês. Em primeiro lugar, há que ter em conta as dinâmicas de competição e cooperação observáveis no palco das Relações Internacionais pois são elas que, em conjugação com os já observados fatores endógenos, explicam que a política externa chinesa seja simultaneamente defensiva, pragmática e assertiva. Essas dinâmicas resultam, por um lado, dos próprios fatores endógenos que condicionam os outros Estados do sistema internacional, ou seja, do conflito ou complementaridade entre os vários contextos e interesses nacionais; e, por outro, das normas vigentes, que definem as regras do jogo na 
cena internacional. Os atores que ambicionam atingir ou manter o estatuto de grande potência geralmente procuram que os outros percecionem que estão a agir de acordo com essas normas, quando selecionam os instrumentos diplomáticos para atingir os objetivos das suas políticas externas. No caso chinês, isto só se verifica quando as normas ocidentais servem os seus próprios interesses; quando isto não acontece, a China avança com normas «com características chinesas", mostrando que os fatores endógenos têm um peso muito maior na formulação da sua política externa do que os fatores exógenos.

Um dos instrumentos diplomáticos que se desenvolveu na segunda metade do século passado e está cada vez mais em voga é o multilateralismo, que privilegia o processo de consulta entre os vários atores de determinado espaço geopolítico. Vimos, na secção anterior, que o Império do Meio não tinha tradição neste processo de consulta, implementando um sistema tributário marcadamente hierárquico revelador do desinteresse no relacionamento com o exterior. Os primeiros anos da República Popular da China também não foram favoráveis ao estabelecimento de relações externas, apesar de Mao Zedong dar os primeiros passos em direção ao multilateralismo na sequência da ligação política que desenvolveu com os países em desenvolvimento. É a aceitação da globalização e o posicionamento da China como uma nação win-win que vêm dar o grande impulso: quando o seu bem-estar interno passou a depender do exterior, devido à implementação de um modelo económico dependente das exportações, a diplomacia chinesa começou a ser mais visível, sendo hoje em dia muito ativa, quer no plano bilateral quer multilateral.

A análise da história chinesa sugere-nos, então, que o multilateralismo não seria atualmente a forma preferencial de relacionamento se a China não estivesse tão agradada com a globalização e se mantivesse a posição hegemónica em que se encontrava no passado. A existência de uma única superpotência é, provavelmente, o fator exógeno que mais influencia a definição da política externa chinesa. 
Não podendo fazer face à hegemonia norte-americana, os líderes chineses optaram por tentar esbater essa hegemonia contrapondo um mundo multipolar como garante da paz mundial e viabilizador dos seus interesses estratégicos de potência emergente:

The multipolarization process may be zigzag, protracted and full of struggles, but this is a historical trend independent of human will. It is in conformity with the common aspirations and interests of the majority of countries and conducive to world peace and security. Our efforts to promote the development of the world towards multipolarization are not targeted at any particular country, nor are they aimed at resstaging the old play of contention for hegemony in history. Rather, these efforts are made to boost the democratization of international relations, help the various forces in the world, on the basis of equality and mutual benefit, enhance coordination and dialogue, refrain from confrontation and preserve jointly world peace, stability and development. (RPC 2003a)

Ora a melhor forma de chegar a esta multipolaridade é reforçando o papel das instâncias multilaterais, onde os vários atores internacionais são ouvidos e podem evitar decisões unilaterais. Assim, o recurso ao multilateralismo surge, não por haver um interesse genuíno chinês de agir de acordo com as normas em vigor mas motivado pelo interesse nacional de combater a hegemonia da potência mais forte. Consequentemente, parece-nos que se algum dia a RPC substituir os EUA nesse papel de superpotência, o multilateralismo e o ideal de um mundo multipolar podem progressivamente esvair-se da retórica chinesa.

Evidenciando a coerência entre discurso e prática, Pequim não se limita a apelar ao reforço das instâncias multilaterais a nível mundial, como a Organização da Nações Unidas e a Organização 
Mundial do Comércio, e dá um impulso significativo à criação de organismos de dimensão mais reduzida em áreas que considera de importância estratégica. É neste âmbito que se insere a dinamização chinesa de fóruns trans-regionais com países africanos: o Fórum China-África (Forum on China-Africa Cooperation - FOCAC), criado em 2000, já conta com 50 Estados membros que reúnem de três em três anos (FOCAC 2010); e o Fórum para a Cooperação Económica e Comercial entre a China e os Países de Língua Portuguesa, conhecido por Fórum Macau por ter o seu secretariado baseado nesta região, criado em 2003 com o objetivo claro de facilitar o relacionamento com um nicho de países africanos (Fórum Macau 2003). Na Ásia, a China participa em todas as organizações da Ásia Oriental Asia-Pacific Economic Cooperation (APEC), Association of Southeast Asian Nations (ASEAN) Plus Three (China, Japão e Coreia), ASEAN Regional Forum (ARF), Council for Security Cooperation in Asia-Pacific (CSCAP) (Godement, 2006: 64) - e na Ásia Central criou em conjunto com a Rússia, em 2001, a Organização de Cooperação de Xangai (Shanghai Cooperation Organization - SCO), que tem ainda como membros o Cazaquistão, Quirgistão, Tadjiquistão e Uzbequistão e como observadores o Irão, a Mongólia, a Índia e o Paquistão (SCO, 2010), e, mais recentemente, o Afeganistão e a Bielorússia. Com o Brasil, a Rússia, a Índia e a África do Sul, a China reivindica maior protagonismo nas principais instituições internacionais, de preponderância ocidental. Este grupo dos BRICS, constituído por países pertencentes a distintas áreas geográficas mas de grande relevância económica e política, ambiciona uma nova ordem multipolar (Mendes, 2014: 237). O Novo Banco de Desenvolvimento dos BRICS, anunciado em 2013 e criado em 2014, terá a sua sede em Xangai. Vocacionado para a criação de infraestruturas e desenvolvimento sustentável (BRICS, 2013: parág. 9), desafia de forma inequívoca a posição do Banco Mundial e Fundo Monetário Internacional, instituições que emergiram do sistema Bretton Woods. 
Uma análise cuidada da participação chinesa nestes organismos, revela a prática de um "multilateralismo lucrativo" (Holslag, 2006: 11), ou seja, de satisfazer os interesses da realpolitik através deste instrumento de soft power - capacidade de influenciar pela persuasão e não pela coerção, ou seja, todas as atividades que ultrapassam o domínio da segurança, como sejam a ajuda humanitária, o investimento económico, a cultura e, neste caso, a diplomacia multilateral (Kurlantzick, 2006: 1). Ao enquadrar o relacionamento no âmbito multilateral, Pequim mostra que respeita o princípio da igualdade no tratamento, a tal "democracia das relações internacionais» (ver discurso oficial chinês sobre a multipolaridade supracitado) que tanto defende - um conceito que não deixa de surpreender, vindo de um país de tradição antidemocrática e apologista das hierarquias. Mas os objetivos da China são bem mais realistas: os fóruns com países africanos são usados para consolidar a sua presença em África, revertendo em proveitos políticos e económicos; e, com a Organização de Cooperação de Xangai, Pequim visa conter os Estados Unidos na Ásia Central e o fortalecimento da Rússia e da Índia. Os líderes chineses têm adotado uma política de grande pragmatismo no relacionamento com estes vizinhos desenvolvendo, por um lado, laços de cooperação na contenção da potência americana e, por outro, tentando impedir a formação de coligações entre eles, numa lógica de competição: por exemplo, a formação de um bloco indo-russo ou o reforço das relações entre a Índia e os EUA, que seriam claramente desvantajosas para a China. Isto mostra o papel que os fatores exógenos - existência de uma superpotência e ressurgimento de duas grandes potências -, nas suas dinâmicas de competição e cooperação, jogam na formulação da política externa chinesa e revela uma visão classicista de criação de balanças de poder quer a nível regional, quer a nível internacional, para contrabalançar a potência hegemónica. 


\section{Relações de reciprocidade}

Outro dos fatores exógenos que influencia a forma de fazer política externa são as relações de reciprocidade que se estabelecem entre os vários atores. A grande preocupação dos líderes chineses em evidenciar esta reciprocidade é visível na fidelidade aos Cinco Princípios da Coexistência Pacífica (ver quadro 2) adotados na década de 1950 e presente em todas as declarações de política externa e na própria Constituição do Estado, de onde ressalta a ideia de relações mutuamente benéficas (win-win). Na prática, os governantes chineses exigem aos líderes das outras potências um tratamento de igual para igual e enquadram as relações com os países do dito 'Sul' numa lógica de reciprocidade. Grande apologista das relações Sul-Sul, a China considera-se, enquanto maior país em desenvolvimento do mundo, disponível para ajudar países africanos e latino-americanos rumo ao desenvolvimento. Porquê este interesse chinês na reciprocidade?

\section{Quadro 2.}

\section{Os Cinco Princípios da Coexistência Pacífica}

1 - Respeito mútuo pela soberania e integridade territorial;

2 - Não agressão mútua;

3 - Não ingerência nos assuntos internos dos outros Estados;

4 - Igualdade;

5 - Benefício mútuo.

$\mathrm{Na}$ verdade, esta retórica do benefício mútuo tem permitido às autoridades chinesas ganhar apoios em regiões de interesse político e estratégico. Em primeiro lugar, não devemos esquecer que a maior parte dos países que têm estabelecido relações diplomáticas com Taiwan são africanos ou latino-americanos; consequentemente, Pequim tem tentado limitar a margem de manobra de Taipé nessas regiões e convencer líderes políticos a mudar o reconhecimento de uma capital para a outra, apesar desta competição estar de certa forma a abrandar. Em segundo lugar, estas regiões são fontes im- 
portantes de matérias-primas, essenciais para manter o crescimento económico, que já vimos ser uma prioridade interna da China, e oferecem novos mercados para as suas exportações, facto particularmente relevante neste contexto de crise e consequente redução do consumo europeu e norte-americano. Em terceiro lugar, os líderes chineses procuram nestas regiões mais apoios para as suas posições nas Organizações Internacionais, como a ONU, e na revisão da hierarquia do sistema internacional. Ao cativar estes países com os Princípios da Coexistência Pacífica, como o benefício mútuo e a igualdade, a China consegue apoios para as 'suas' normas, como o respeito pela soberania e integridade territorial e a não ingerência nos assuntos internos dos outros Estados:

The basic norms governing international relations on equality of sovereignty and non-interference in each other's internal affairs between the member states as stipulated in the Charter of the United Nations are absolutely not outdated. The history and culture, social systems and development models of various countries should be respected. (RPC 2003a)

A este respeito há um fator exógeno importante que influencia a política externa chinesa: a postura ocidental relativamente a questões que Pequim considera do foro interno, como seja o (des) respeito pelos direitos humanos, a questão do Tibete e do Xinjiang e o conflito com Taiwan. Revelando total incompreensão pelo «espírito missionário" ocidental, parte da reação da China passa por tentar que os restantes atores do sistema internacional adotem os, já referidos, princípios que considera basilares no enquadramento das Relações Internacionais, tentando 'achinesar' as normas ocidentais ditas 'universais'.

O princípio da não-ingerência nos assuntos internos leva a uma política de incondicionalidade (no-strings-attached) no relaciona- 
mento com os outros Estados, não exigindo o respeito de normas de boa governação ou respeito pelos direitos humanos. Assim, em troca da Ajuda Pública ao Desenvolvimento, por exemplo em África e na América Latina, a China apenas pede contrapartidas económicas ou apoio político, ao contrário do mundo ocidental que faz depender a ajuda de exigências que muitos líderes ditatoriais e corruptos não têm interesse em cumprir:

As a member of the developing countries, China is ready to develop extensive and in-depth cooperation in economic, scientific and technological, educational and cultural fields on the basis of the principles of equality and mutual benefit, emphasis on results, varied forms and common development. China stands ready to offer assistance within its capacity to developing countries having difficulties. Although China's aid is limited, it is provided sincerely and without any conditions attached. (RPC 2003b)

Este "Consenso de Pequim» apresenta uma fórmula para atingir o desenvolvimento radicalmente diferente da proposta pelo "Consenso de Washington", defendendo um modelo que contradiz a ideia de liberalização política ou reformas económicas como condições fundamentais para o desenvolvimento de longo prazo, privilegiando o comércio e investimento em infraestruturas e instituições sociais (Thompson, 2008: 15). Este choque de 'consensos' faz-nos regressar ao conceito de soft power: o poder de atração da República Popular da China em determinadas regiões do globo tem aumentado de forma proporcional à sua emergência económica, com base nesta lógica da reciprocidade espelhada no slogan da cooperação Sul-Sul (ver citação anterior). Percecionada como um parceiro mais conveniente, Pequim desafia os interesses norte-americanos e europeus na América Latina e em África, regiões que as potências ocidentais há muito consideram os seus "pátios traseiros». Na América Latina, 
os Estados Unidos perderam terreno quando concentraram esforços no Médio Oriente na sequência do 11 de setembro de 2001, negligenciando a região e permitindo a consolidação da presença chinesa, facto que muito agradou às elites locais antiamericanas. Quanto a África, tornou-se a questão mais sensível nas relações sino-europeias: apesar das exportações africanas para a China estarem a aumentar, a Europa é ainda de longe o maior parceiro comercial do continente africano (Fox e Godement, 2009: 41) e as antigas potências coloniais temem a capacidade chinesa de capitalizar a presença económica para obter influência política (Holslag, 2006: 11). Mais importante ainda, a União Europeia (UE) preocupa-se com o facto de a China começar a ser percecionada como o soft power em África, apresentando-se como um parceiro e não como um guia e oferecendo um modelo mais atrativo do que o europeu, que exige o respeito das chamadas normas 'universais'. A confirmar-se esta tendência a UE, cuja política externa é baseada em linhas diretrizes normativas, moldando o que é considerado 'normal' em Relações Internacionais (Burton, 2009: 12-14), vê limitada a sua capacidade de exportar o modelo transnacional baseado nos seus valores, ou o que pode ser apelidado de "visão democrática cosmopolita" princípios ocidentais de liberalismo, democracia e mercado livre (Coker, 2007: 30, 33).

\section{Considerações finais}

Este capítulo ofereceu um enquadramento histórico-conceptual que facilita a análise da atuação da República Popular da China no xadrez geopolítico contemporâneo, permitindo entender as diferentes linhas de decisão e atuação em contextos diferenciados, nomeadamente através da análise dos fatores endógenos e exógenos com impacto no processo de tomada de decisão chinês. A conjugação 
do fator exógeno da imposição ocidental de normas reguladoras das políticas externas estatais com o fator endógeno da vitimização perante as humilhações provocadas pelas potências ocidentais (e Japão), num momento de reemergência chinesa, leva Pequim a questionar a hegemonia ocidental em ditar as regras de relacionamento internacional. Como as normas 'universais' são, maioritariamente, uma criação dos governos ocidentais, os líderes chineses não estão particularmente interessados em segui-las, preferindo substituí-las pelas suas próprias diretrizes (Coker, 2007: 33):

China unswervingly pursues an independent foreign policy of peace. The fundamental goals of this policy are to preserve China's independence, sovereignty and territorial integrity, create a favorable international environment for China's reform and opening up and modernization construction, maintain world peace and propel common development. [...] The Five Principles of Peaceful Coexistence and the universally recognized norms governing international relations should serve as the basis for setting up the new international political and economic order. [...] China is ready to establish and develop friendly relations of cooperation with all the countries on the basis of mutual respect for sovereignty and territorial integrity, mutual non-aggression, mutual non-interference in each other's internal affairs, equality and mutual benefit, and peaceful coexistence. (RPC, 2003c)

De forma hábil, a política externa chinesa define o sistema normativo de acordo com os seus interesses desenvolvendo, com grande pragmatismo, uma visão seletiva do multilateralismo e da incondicionalidade nas relações bilaterais. Mas fá-lo com a subtileza de quem aprendeu depressa com o discurso hipócrita ocidental: afinal, as suas normas apenas reiteram o legado dos Tratados de Vestefália (1648), um sistema baseado na afirmação formal da soberania esta- 


\section{tal, integridade territorial e não interferência nos assuntos externos dos outros Estados, limitando-se a pôr em prática os ensinamentos ocidentais, não é verdade?}

\begin{tabular}{|l|}
\hline Quadro 3. \\
\hline Questões para análise \\
\hline $\begin{array}{l}\text { De que forma o papel dos líderes tem condicionado/projetado a política externa chinesa? Que } \\
\text { consequências se esperam do «Sonho chinês" de Xi Jinping? }\end{array}$ \\
Analise o binómio ideologia/pragmatismo na política externa chinesa; por exemplo, parece-lhe \\
que a China enquadra o relacionamento com África e América Latina no âmbito da cooperação Sul- \\
Sul por razões ideológicas ou económicas? \\
\hline $\begin{array}{l}\text { Será que a ajuda chinesa ao desenvolvimento constitui uma alternativa à agenda de desen- } \\
\text { volvimento ocidental? A exportação do modelo de desenvolvimento chinês para o Sul é viável? }\end{array}$ \\
$\begin{array}{l}\text { Considera que a postura chinesa no plano internacional questiona as normas internacionais } \\
\text { vigentes? }\end{array}$ \\
A clara preferência chinesa pelo multilateralismo revela um interesse genuíno em atingir \\
um mundo multipolar ou esconde objetivos hegemónicos? Haverá uma partilha destes objetivos \\
(pacíficos ou hegemónicos) com outras potências, como por exemplo a Rússia e a Índia no quadro \\
da Organização de Cooperação de Xangai ou ainda com o Brasil, visível nas posições conjuntas \\
dos BRICS no âmbito das instituições de Bretton Woods? Qual o impacto do 'Novo Banco de \\
Desenvolvimento' dos BRICS no sistema internacional?
\end{tabular}

\begin{tabular}{|l|}
\hline Quadro 4. \\
\hline Fontes na internet \\
\hline Agência (oficial) Noticiosa Nova China - Xinhua, http://www.xinhuanet.com/ \\
\hline Internet Guide for Chinese Studies, http://sun.sino.uni-heidelberg.de/igcs/ \\
\hline Jornal (oficial) Chinês - China Daily, http://www.chinadaily.com.cn/ \\
\hline Ministério da Defesa da República Popular da China, http://eng.mod.gov.cn/ \\
Ministério dos Negócios Estrangeiros da República Popular da China, http://www.fmprc.gov. \\
cn/eng/
\end{tabular}

\begin{tabular}{|c|}
\hline Quadro 5. \\
\hline Leituras recomendadas \\
\hline $\begin{array}{l}\text { Callahan, William (2013) China dreams: } 20 \text { views of the future. New York: Oxford University } \\
\text { Press. }\end{array}$ \\
\hline Cunha, Luís (2012) A Hora do Dragão. Lisboa: Zebra Publicações. \\
\hline $\begin{array}{l}\text { D'Hooghe, Ingrid (2014) China's Public Diplomacy. Leiden: Martinus Nijhoff Publishers / Brill } \\
\text { Academic Publi. }\end{array}$ \\
\hline $\begin{array}{l}\text { Golden, Sean (2012) China en Perspectiva: Análisis e interpretaciones. Biblioteca de China } \\
\text { Contemporânea. Barcelona: Edicions Bellaterra. }\end{array}$ \\
\hline $\begin{array}{l}\text { Mendes, Carmen Amado (2013) Portugal, China and the Macau Negotiations, 1986-1999. } \\
\text { Hong Kong: Hong Kong University Press. }\end{array}$ \\
\hline $\begin{array}{l}\text { Wang Gungwu (2014) Another China Cycle: Committing to Reform. Singapore: World Scientific } \\
\text { Publishing. }\end{array}$ \\
\hline
\end{tabular}




\section{Bibliografia}

Bond, Michael H. (org) (2008) The Psychology of the Chinese People, Hong Kong: The Chinese University Press.

BRICS (2013) «Fifth BRICS Summit Declaration and Action Plan». [http://www.brics5. co.za/fifth-bricssummit-declaration-and-action-plan/] (consultado a 14 de março de 2015).

Burton, Benjamin (2009) "EU-China-Africa Trichotomy: The EU, China and the Normative Power Concept on the African Continent", EU-China Observer, Issue 3, College of Europe, 12-17.

Coker, Christopher (2007) «Strangers at the Gate: Africa, the Challenge of China and the Eclipse of the West", in Franco, Manuela (org), Estratégia e Segurança na África Austral. Lisboa: Fundação Luso-Americana e Instituto Português de Relações Internacionais.

Dillon, Michael (2009) Contemporary China - An Introduction. New York: Routledge.

FOCAC (2010) «Forum on China-Africa Cooperation». [http://www.focac.org/eng/] (consultado a 14 de março de 2015).

Ford, Christopher Ashley (2010) The Mind of Empire: China's History and Modern Foreign Relations. Lexington: The University Press of Kentucky.

Fórum Macau (2003) "Fórum para a Cooperação Económica e Comercial entre a China e os Países de Língua Portuguesa (Macau)». [http://www.forumchinaplp. org.mo] (consultado a 14 de março de 2015).

Fox, John; Godement, François (2009) A Power Audit of EU-China Relations. Londres: European Council on Foreign Relations.

Godement, François (2006) "Neither hegemon nor soft power: China's rise at the gates of the West", in Zaborowski (org), Facing China's rise: Guidelines for an EU strategy, Chaillot Paper 94, Institute for Security Studies, European Union, dezembro, 51-70.

Holslag, Jonathan (2006) "The EU and China: The Great Disillusion", Asia Paper, Brussels Institute of Contemporary China Studies, 1(3), 5 novembro.

Kurlantzick, Joshua (2006) "China's Charm: Implications of Chinese Soft Power", Policy Brief 47, Carnegie Endowment for International Peace, junho, 1-8.

Mendes, Carmen Amado (2010) "A China e a Cooperação Sul-Sul», Relações Internacionais, 26, 39-46.

Mendes, Carmen Amado (2013) "A Relevância do Fórum Macau: o Fórum para a Cooperação Económica e Comercial entre a China e os Países de Língua Portuguesa", Nação e Defesa, 134, Instituto da Defesa Nacional, 279-296.

Mendes, Carmen Amado (2014) "Macau in China's Relations with the Lusophone World", Revista Brasileira de Politica Internacional, 57, 225-242.

Rios, Xulio (2005) (org) Política Exterior de China - La diplomacia de una potencia emergente. Barcelona: Bellaterra.

Robinson, Thomas; Shambaugh, David (1998) (org) Chinese Foreign Policy - Theory and Practice. Oxford: Oxford University Press. 
RPC - República Popular da China (2003a) «China's Views on the Development of Multipolarization", Ministério dos Negócios Estrangeiros, 18 de agosto, [http:// www.fmprc.gov.cn/eng/wjdt/wjzc/t24880.htm] (consultado a 14 de março de 2015).

RPC (2003b) "China's Stand on South-South Cooperation", Ministério dos Negócios Estrangeiros, 18 de agosto, [http://www.fmprc.gov.cn/eng/wjdt/wjzc/t24884.htm] (consultado a 14 de março de 2015).

RPC (2003c) “China's Independent Foreign Policy of Peace», Ministério dos Negócios Estrangeiros, 18 de agosto, [http://www.fmprc.gov.cn/eng/wjdt/wjzc/t24881.htm] (consultado a 14 de março de 2015).

Sanjuan, Thierry (2009) (org) Compreender a China Contemporânea - um dicionário. Lisboa: Edições 70.

Shirk, Susan (2008) China - Fragile Superpower. Oxford: Oxford University Press.

Thompson, Drew (2008) «Economic growth and soft power: China's Africa strategy», in Waldron, Andrew (org), China in Africa. Washington: The Jamestown Foundation.

SCO (2010) «Shanghai Cooperation Organization». [http://www.sectsco.org] (consultado a 14 de março de 2015).

Spence, Jonathan (1998) The Chan's Great Continent - China in Western Minds. Nova Iorque: Norton \& Company.

Wang Gungwu; Zheng, Yongnian (2008) (org) China and the New International Order. Nova Iorque: Routledge.

Xi Jinping (2014) Discurso na UNESCO, 28 de março, Ministério dos Negócios Estrangeiros da República Popular da China. [http://www.fmprc.gov.cn/mfa_eng/ wjdt_665385/zyjh_665391/t1142560.shtml] (consultado a 14 de março de 2015).

Zhang Wei-Wei (2012) The China Wave: Rise of a Civilizational State. Hackensack: World Century Publishing Corporation. 